\title{
Neural activity associated with executive functions in adolescents with attention-deficit/hyperactivity disorder (ADHD)
}

\author{
Nele Wild-Wall ${ }^{\text {b, }}{ }^{*}$, Robert D. Oades ${ }^{a}$, Marion Schmidt-Wessels ${ }^{a}$, Hanna Christiansen ${ }^{a}$, \\ Michael Falkenstein ${ }^{b}$
}

\section{International Journal of Psychophysiology, 74, 19-27}

This is the reformatted manuscript submitted - prior to publication in its final form at doi:10.1016/j.ijpsycho.2009.06.003

a Biopsychology Group, Clinic for Child and Adolescent Psychiatry and Psychotherapy, University of Duisburg-Essen, Virchowstr. 174, 45147 Essen, Germany

b Leibniz Research Centre for Working Environment and Human Factors, Institute of Occupational Physiology, University of Dortmund, Ardeystr. 67, 44139 Dortmund, Germany

* Correspondence: wild-wall@ifado.de

Keywords: Attention-deficit hyperactivity disorder, ADHD; Inhibition; ERP; Error negativity; Executive function

Acknowledgments: We acknowledge support from the International Multicentre ADHD Genetics project (IMAGE), NIH grant R01MH62873 to Dr. S.V. Faraone. We also want to thank Ludger Blanke for his most capable technical support

\section{ABSTRACT:}

This study used event-related potentials (ERPs) and flanker-task performance to compare executive functions in adolescents with ADHD, their siblings and independent healthy controls. The aim was to investigate the processing of distracting stimuli, control over inappropriate responses, and the detection of errors in the presence of incompatible and No-go stimuli (arrow-heads and a circle, respectively).

Performance showed no major differences between the groups, although No-go errors were numerically increased for the patients. Adolescents with ADHD were not characterised by the absence of post-error response slowing. The ADHD group showed a generally smaller $\mathrm{N} 2$ and a missing amplification of the frontal P3 (P3a) in No-go vs. incompatible trials most likely reflecting impaired inhibitory processing. In response-locked potentials error-related negativity $(\mathrm{Ne})$ and positivity $(\mathrm{Pe})$ did not clearly differentiate between the groups".

This study shows that ADHD children are more impaired in controlled than automatic response processing and inhibition. This was particularly evident in reduced frontal activity in general and especially after No-go stimuli. Deficient error processing may, however, not be a cardinal feature of adolescents with ADHD. Future work must orient towards determining if there is a subgroup for whom the inhibitory impairment is characteristic.

\# Note (RDO): But Ne amplitude in the ADHD group was smaller than in the combined control and sibling groups

\section{INTRODUCTION}

To attend to target stimuli and not be distracted by irrelevant signals is an efficient way to perform a task. It also helps to be aware of mistakes so that one can correct them and maintain efficiency.
Youngsters with attention-deficit/ hyperactivity disorder (ADHD) typically have difficulties with maintaining the focus of attention (Konrad et al., 2004), are often distracted by unimportant 
stimuli (Lawrence et al., 2002), have problems with inhibiting premature responses (Overtoom et al., 2002) and are claimed to monitor their performance for errors less well than those without ADHD (Siklos and Kerns, 2004; Schachar et al., 2004). Thus it is not surprising that these children perform poorly on tasks requiring effort and control both in the laboratory and at school (Spira and Fischel, 2005; Konrad et al., 2006). A better understanding of how these children suppress irrelevant information, control irrelevant responses, and process their mistakes would be helpful. This is especially pertinent considering that improvements of cognitive performance following the usual treatment with indirect catecholamine agonists (the psychostimulants) are attributed to early stages in information processing affected by alertness and are not evident in terms of academic and work performance (Loe and Feldman, 2007). Thus, a link between the deficits in information processing/ executive control processes and a deficient (fronto-striatal) dopamine system has been extensively discussed (Biederman, 2005; Swanson et al., 2007).

In this study event-related potentials (ERPs) as quantitative measures of the performance of these executive processes in the brain are applied to these questions. We assess separately both the processing of relevant and irrelevant stimuli in stimulus-related ERPs, and the ERP registration of correct and incorrect motor responses to these stimuli.

An essential feature of the initial response to a stimulus is that it should be correctly classified and, if irrelevant to the task in hand, inhibitory processes brought into play. An excellent paradigm is the Go/No-go task where the No-go stimulus elicits ERPs such as the N2 that reflects these classification and inhibitory processes (Folstein et al., 2008; Dong et al., 2009). No-go stimuli often precipitate premature behavioural responses (errors) that allow the normal ERP markers of monitoring success in processing and response to be studied (Falkenstein et al., 2001).

For example, Smith et al. (2004) reported a series of changes in the early components recorded from children with ADHD on No-go trials, namely alterations in amplitude and topography of the P1, N1, P2, N2 and P3 ERPs. In particular, the N2 component, with a frontal/frontocentral maximum has been linked to conflict monitoring, and is marked on successful trials (Yeung et al., 2004). Following a No-go stimulus, the N2 was shown in healthy adults to be as large on trials with imagined as well as actual response inhibition, and has thus been viewed as representing a premotor process of a cognitive nature (Burle et al., 2004). However, N2 has also been related to the degree of ambiguity (Szmalec et al., 2008), the perceptual distinction between stimuli (Azizian et al., 2006) and the surprise or expectancy of the event (Gajewsky et al., 2008) which all relate to processes of classification. While N2 clearly indexes processes crucial to response selection, it is followed in Go/No-go tasks by a P3-like positivity with fronto-central maximum (Falkenstein et al., 2002; Kamarajan et al., 2005) that will be referred to here as $\mathrm{P3a}$. This component has been associated with motor inhibition or the (re-)evaluation of an appropriate motor plan for No-go stimuli (Bruin and Wijers, 2002) and may be particularly marked on trials where the cues are incongruent (Gomes et al., 2008).

Several studies have reported small, not always clearly significant reductions of N2 amplitude on stop and No-go trials in patients with ADHD, largely independent of successful response inhibition in children with a mean age of $10-11$ years 
(Brandeis et al., 1998; Dimoska et al., 2003; Broyd et al., 2005; Albrecht et al., 2005; Wiersema et al., 2006; Johnstone et al., 2007; Liotti et al., 2007) adolescents (mean 15.7 years, Groom et al., 2008) and young adults (Fallgatter et al., 2005). But others emphasize there were no altered amplitudes or slight increases inpatients with mean ages of 10-11 years (Oades et al., 1996; Henriquez et al., 2006) or young adults (Prox et al., 2007; Ohlmeier et al., 2007). Findings in ADHD are also heterogeneous for the P3 component. P3 amplitudes often tend to be reduced by comparison to controls (Overtoom et al., 2002; Liotti et al., 2005; Fallgatter et al., 2005; Brandeis et al., 1998; Bekker et al., 2005; Prox et al., 2007), but no differences or even a larger signal have also been described (Dimoska et al., 2003; Henriquez et al., 2006; Johnstone et al., 2007; Groom et al., 2008). Only two laboratories have used a flanker task similar to that reported in the current study. Incongruent trials and those producing an error tended to increase N2 (and P3) amplitude in healthy and ADHD groups (Jonkman et al., 1999, 2007; Albrecht et al., 2008), whereby Albrecht et al. (2008) reported a smaller enhancement of the $\mathrm{N} 2$ amplitude in ADHD patients. We were therefore concerned in the present study to clarify these associations.

Monitoring that a response was correct and detecting the commission of an error are the central nervous processes that should follow the stimulus-locked events just described, and are best studied in the response-locked ERP. On making an error, two major components usually follow. The first is a negative deflection $50-100 \mathrm{~ms}$ after the response over frontal brain areas (error negativity, $\mathrm{Ne}$, or error-related negativity, ERN). The second is a plateaulike positive deflection which follows over more posterior regions (error positivity, Pe) (Falkenstein et al., 1991; Gehring et al., 1993; Falkenstein et al., 2000). These authors suggested that the Ne reflects a mismatch between the expectation and the outcome of the response. As its amplitude appears independent of the degree of mismatch or conflict it has been suggested to constitute an alerting signal for the relevant parts of the brain to reinstitute efficient control (Carbonnell and Falkenstein, 2006; Masaki et al., 2007). The need for this may arise, for example, through the conflict between response alternatives. In contrast, it is argued that the Pe arises only when the subject is aware of having made an error and this error has some motivational significance (Leuthold and Sommer, 1999; Nieuwenhuis et al., 2001; O'Connell et al., 2007; Endrass et al., 2007; review of alternative explanations in Overbeek et al., 2006). A number of studies on the development of error-related processing across puberty, through adolescence to young adulthood (7-24 years of age) have been carried out (Segalowitz and Davies, 2004; Davies et al., 2004; Ladouceur et al., 2004; Hogan et al., 2005; Santesso et al., 2006; Wiersema et al., 2007). The tasks used by the 4 laboratories in these 6 studies have concerned letter- and arrow flanker (Eriksen and Eriksen, 1974; Kopp et al., 1996a), coloured arrow discrimination and letter-Go/No-go paradigms, respectively. These studies describe a general increase of $\mathrm{Ne}$ amplitude with increasing age, while the $\mathrm{Pe}$ amplitude does not change. Only one study reported that $\mathrm{Pe}$ amplitude increased across adolescence before falling slightly in young adulthood (Ladouceur et al., 2007).

These studies also report on the development of a behavioural index of 'awareness' that an error has been committed. The reaction time (RT) on the first correct response after an error is usually slower than that recorded on successive correct responses (Rabbitt, 1966). While RTs vary considerably within and between children of different ages, 
these developmental studies reported that the post-error RT was either slower for all age-groups studied (Davies et al., 2004; Santesso et al., 2006; Wiersema et al., 2007) or the slowing effect increased with age (Hogan et al., 2005). However, it has been claimed that an absence of posterror-slowing is characteristic of ADHD children (Sergeant and van der Meere, 1988). Indeed, Ladouceur et al. (2007) emphasized that the error-related ERP components studied were dependent on trials where the post-error slowing was evident. This feature may be crucial to interpretations of patients' ERPs, even though Wiersema et al. (2007) found no formally significant correlations between post-error RTs and measures of the $\mathrm{Ne}$ or Pe. In contrast, Debener et al. (2005) found a clear correlation between the $\mathrm{Ne}$ amplitude and posterior slowing on the level of single trials. Also, an association of post-error slowing with $\mathrm{Pe}$ amplitude has been reported for healthy adults (Nieuwenhuis et al., 2001; Hajcak et al., 2003).

Six groups have reported heterogeneous findings on error-related processing in children with ADHD (aged 714 years, means 10-11 years) on 4 different tasks. Liotti et al. (2005) first described reduced $\mathrm{Ne}$ amplitudes on failed trials in a stop-task. Similarly, on the arrow-flanker task Van Meel et al. (2007) found that the Ne amplitude was reduced despite the patients retaining normal post-error RT slowing. This has recently been confirmed by Albrecht et al. (2008). In contrast, Wiersema found no $\mathrm{Ne}$ differences between groups on a Go/Nogo or a two stimulus RT-task even though the patients did not show the normal post-error slowing of RT. However, the $\mathrm{Ne}$ components were not only similar, but extremely small in both the comparison and study groups. Burgio-Murphy et al. (2007) described a quite different pattern for children with combined or inattentive subtypes of ADHD on a continuous performance task. While post-error RT slowing in the ADHD groups was absent, the $\mathrm{Ne}$ was largest in the combined type group, somewhat smaller in the inattentive subgroup, but smaller again in the controls. Further, the topography of the $\mathrm{Ne}$ was more posteriorly distributed than usual. Results for the $\mathrm{Pe}$ in children with ADHD show either that there is no difference compared to healthy controls (Burgio-Murphy et al., 2007; Albrecht et al., 2008) or that there is a marked reduction in the patients (Wiersema et al., 2005; Jonkman et al., 2007). In some of the studies it is unclear whether the observed changes are specific for error trials, because ERPs in correct trials are not considered. Clearly, the nature of the $\mathrm{Ne}$ and $\mathrm{Pe}$ in ADHD and the specificity of the result for error trials require further study.

The present study was planned to overcome some of the methodological inconsistencies of the foregoing studies (e.g. the nature of the $\mathrm{Ne} / \mathrm{Pe}$ measurement, role of stimulus-locked N2) in a group of youngsters with the combined type of ADHD across the age range used in the developmental investigations (above). To study the processing of relevant and irrelevant stimuli we used an arrow-head flanker task (Eriksen and Eriksen, 1974) modified to present trials with incongruent cues and No-go stimuli for which ERPs could be recorded for the error responses central to this study. These are the commission of an incorrect response, and the commission of any response, respectively (Kopp et al., 1996a). The high error rate on this task is elicited by incongruent arrowheads presented asynchronously alongside the target that enhance the wrong left- or right-handed response, and by neutral stimuli in the target area that require no response (No-go stimuli) and facilitate false alarms. 
We introduce three elements in to the ERP analysis that should represent improvements on the techniques applied to date. Firstly, the distracting stimuli in the flanker task were introduced $160 \mathrm{~ms}$ prior to the target to enhance the tendency to elicit errors. Secondly incongruent and No-go stimuli were presented in the same task to enable a comparison of different types of executive control, namely the automatic/ unconscious control after incongruent stimuli, and the conscious control after No-go stimuli. The presentation of both conditions within one block avoids the potential confounds of altered states of alertness and motivation in subjects presented with the conditions in two separate tasks. Thirdly, to demonstrate the specificity of the expected changes for error trials, response-locked ERPs on correct trials were also analysed. Even on correct trials a small negative deflection is usually observed that probably reflects response monitoring (correct-related negativity, Nc; Vidal et al., 2003; Allain et al., 2004) and for which a similar source to the $\mathrm{Ne}$ has been reported (Yordanova et al., 2004). Not only is there an interest integral to a group comparison for the $\mathrm{Nc}$, but the functional aspect of the Ne should be viewed in terms of its amplitude with respect to the Nc. Only a specific change of the $\mathrm{Ne}$ in error trials but not of the $\mathrm{Nc}$ in correct trials would suggest an alteration of error processing in ADHD.

Finally, as we predicted that the $\mathrm{Ne} / \mathrm{Pe}$, as well as the N2-P3 ERP complexes would at least in part be reduced in the patients compared to the controls, a group of healthy siblings of the ADHD patients was included in anticipation that they would show a phenotype reflecting that seen in ADHD but with ERP amplitudes intermediate between those shown by controls and patients for $\mathrm{N} 2$ and $\mathrm{Ne}$, as claimed by Albrecht et al. (2008). This is a reasonable prediction considering that about $60 \%$ of the variance in $\mathrm{N} 2$ and $\mathrm{P} 3$ amplitudes has been attributed to genetic influences (Anokhin et al., 2004) and the heritability of ADHD is about $70 \%$ (Faraone et al., 2005b). This would provide a significant step towards describing the neural basis for an endophenotype for an aspect of anomalous cognitive processing in ADHD.

\section{METHOD}

\subsection{Participants}

As part of an ongoing genetic study $\left(\right.$ (IMAGE1 $^{1}$ ) a small subset of 15 children with DSM-IV ADHD combined type (mean age $=13.9$ years, range: $11.5-17.5$ ) were recruited for this study following referral to the Clinic in Essen along with 12 of their healthy siblings (SIB: mean age $=14.5$ years, range: 12.0-17.1). In addition, 12 unrelated healthy children without a family history of ADHD were recruited as a control group by advertisement (CON: mean age $=13.2$ years, range: $11.2-15.9$ ) . Diagnoses were based on a standardized, semi-structured interview with the parents (Parental Account of Childhood Symptoms, [PACS]; Taylor et al., 1991; Chen and Taylor, 2006). ADHD symptoms in both cases and siblings were rated with the long version of Conners' parent and teacher rating scales (CPRS-R:L; CTRS-R:L; Conners, 2002), and the parent and teacher versions of the Strengths and Difficulties Questionnaires (SDQ; Goodman, 1997). Exclusion criteria for both cases and siblings included autism, epilepsy, general learning difficulties, brain disorders and any genetic or medical disorder associated with externalizing behaviour that mimics ADHD. There were no cases with comorbid obsessive compulsive disorder, tic disorder, dyslexia, enuresis or encoporesis, but there were signs of anxiety, oppositional and conduct

\footnotetext{
${ }^{1}$ International Multicentre ADHD Genetics project (Faraone et al., 2005a).
} 
disorders in 7, 8 and 4 sometimes overlapping cases, respectively. All subjects had an estimated IQ N75 based on 4 WISC subtests (information, picture arrangement, similarities and block design; Sattler, 1992) taken at the time of testing. All families were provided with a small honorarium in addition to their expenses which was not dependent on any condition. Following approval by the Clinic Management and Ethics Committee of the Faculty of Medicine, full written information was provided to the parents/ guardians and children, and their verbal and written consent was obtained in accordance with the Helsinki Declaration.

\subsection{Stimuli and procedure}

Participants were seated in a dimly lit room $1 \mathrm{~m}$ in front of a computer monitor. In the flanker task (modified after Kopp et al., 1996a) arrow-heads were presented as targets in the centre pointing with equal probability to the left or right. They were flanked by two further arrow-heads in the vertical axis that appeared 160 ms before the target. In the compatible condition (COMP: $60 \%$ of trials) flankers and targets pointed in the same direction; in the incompatible condition (INCOMP: $20 \%$ of trials) they pointed in opposite directions. In the remaining $20 \%$ of trials a circle (with flankers) was presented centrally instead of the target indicating that response should be withheld (No-go condition). For each of the three conditions, half of the flankers pointed to the left or right, respectively. The 3 conditions were presented in a pseudo-random order. Participants were instructed either to press the left or right button of a response pad according to the direction indicated by the central arrow-heads as fast and as accurately as possible, or to withhold the response in the No-go condition. In total, 840 trials were presented with a short break after each block of 105 trials.

Each stimulus was white on a dark gray background and obtained an area of $1.5 \times 1.5 \mathrm{~cm}$. The vertical stimulus array was $5.5 \mathrm{~cm}$ long. Each trial started with a small circle as a fixation stimulus in the middle of the screen. It was replaced after $500 \mathrm{~ms}$ by the flankers and followed by the target after $160 \mathrm{~ms}$. Target and flankers were presented for 300 ms after the target onset. The inter-trial interval was fixed at $1600 \mathrm{~ms}$. To reduce the trialto-trial variation in information processing and in the ERPs elicited, moderate time pressure was applied; a feedback tone was given if the reaction time (RT) exceeded $600 \mathrm{~ms}$. The flanker task was embedded in a task battery of two other cognitive tasks (auditory oddball task, time estimation task) which will be reported elsewhere. All tasks were performed during one 45minute session and the same task sequence between participants with short participant-determined breaks of about 1 $\min$.

\subsection{Data processing}

Performance was assessed with measures of the RT and error rate. The EEG was recorded with tin electrodes in the positions of the extended international 10-20 System: F3, F4, C3, C4, P3, P4, F7, F8, T3, T4, T5, T6, Cz, Fz, Pz, FCz, CPz, CP3, CP4, FC3, FC4, TP7, TP, FPz, Oz, FT7, FT8, M1, and M2. Horizontal and vertical electrooculograms (EOG) were recorded from electrodes placed at the outer canthi (LO1, LO2) as well as above and below the right eye (SO2, 102). The ground electrode was located at the AFz electrode and $\mathrm{M} 1$ was used as the primary reference. Later the averaged data were re-referenced to linked mastoids (M1 + $\mathrm{M} 2$ ). Electrode impedances were kept below $5 \mathrm{k} \Omega$. The EEG was recorded and sampled at $500 \mathrm{~Hz}$ using a DC coupled amplifier (SYNAMPS) and recording software (ACQUIRE; both Neuroscan Inc.). High- and low-pass filters were set at .1 and $100 \mathrm{~Hz}$. 
Only trials with RTs of 100-600 ms were included in the data analysis. EEG data were analysed offline with Vision Analyzer software (Brain Products, Munich). A digital low-pass filter was set at $30 \mathrm{~Hz}$ (24 dB/octave). Stimulus-locked epochs were $1600 \mathrm{~ms}$ long (relative to target onset $-500 \mathrm{~ms}$ and $+1100 \mathrm{~ms}$ ). The mean amplitude of the pre-target interval between -260 and $-160 \mathrm{~ms}$ (between $-100 \mathrm{~ms}$ and flanker onset) was used as baseline. All epochs with EEG amplitudes over $150 \mu \mathrm{V}$ or with drifts of more than 50 $\mu \mathrm{V}$ from one sampling point to the next were discarded. Correction for eye movements was computed by a regression-based method using the horizontal and vertical EOG (Gratton et al., 1983). Stimulus-locked epochs were averaged for correct trials only, according to condition (COMP, INCOMP, NO-GO). The response-locked epochs covered a $900 \mathrm{~ms}$ period from $-500 \mathrm{~ms}$ before to $+400 \mathrm{~ms}$ after the response in the incompatible condition. They were averaged separately for correct and incorrect responses. The mean number of incompatible trials with correct responses was 115 ( $S D=23.5 ; \quad M I N=64, M A X=151$ ) and for errors was 28 ( $S D=15.6 ; \mathrm{MIN}=10$, $M A X=115)$. For the response-locked epochs a pre-response baseline was set between $-100 \mathrm{~ms}$ until the response.

\subsection{Data analysis}

The irrelevant flanker stimuli were separated in time from the targets in order to produce an uncontaminated ERP record. The peak amplitudes and latencies of the stimulus-locked frontal N2 component were determined at 6 frontal electrodes (F3, Fz, F4, FC3, FCz, and FC4) within a search interval between 200 and $450 \mathrm{~ms}$ after stimulus onset. The P3a, maximal at $\mathrm{FCz}$, was quantified as the mean amplitude in the time interval surrounding the component's peak in the grand average (390 to $450 \mathrm{~ms}$ after target onset). Mean amplitudes were calculated for analysis because especially for the COMP condition a peak could not be reliably determined. Response-locked epochs were used to quantify $\mathrm{Ne}$ for incorrect trials, Nc for correct trials, and the subsequent positivity following errors and correct responses (Pe and Pc, respectively; see Falkenstein et al., 2000 for a tutorial). The waveform showed that $\mathrm{Ne}$ and $\mathrm{Nc}$ were maximal at $\mathrm{FCz}$ (Fig. 3). Thus, $\mathrm{Ne}$ and $\mathrm{Nc}$ amplitudes were determined as the maximal negative peak in the search interval from -50 to $+200 \mathrm{~ms}$ (Falkenstein et al., 2001). Peak latencies of $\mathrm{Ne}$ and Nc were also measured. The early and late parts of the slow-going $\mathrm{Pe}$ and $\mathrm{PC}$ potentials, maximal at $\mathrm{Cz}$ were quantified as the mean amplitude in the time interval from 200 to $250 \mathrm{~ms}$ and 250 to $350 \mathrm{~ms}$ after the incorrect response. Both early and late $\mathrm{Pe}$ and $\mathrm{Pc}$ were measured relative to a pre-response baseline of $100 \mathrm{~ms}$ length.

\subsection{Statistical analysis}

Characteristics of the group and group differences (age, IQ and Conners' rating scales) were examined by analyses of variance with cases, siblings and controls as between-subjects factor (ADHD, SIB and CON: Table 1). For RTs, first groups were compared with the within factor of the two compatibility conditions, then with the within-factor sequence for serial correct responses vs. correct responses after errors of commission. The analysis of error rates included, along with the within-factor of compatibility, the extra level of the No-go condition.

Statistical ERP analyses were based on mean values and used repeated measures ANOVAs. As the gender of the participants was unequally distributed over the experimental groups, gender (male, female) was included as a covariate in all main ANOVAs in order to statistically control for its influence. Although the 
experimental groups did not significantly differ in their age, linear regressions were conducted on each experimental variable in order to control possible influences of age. These regressions were not significant and are not reported.

For analyzing the amplitude and latency of the N2 component two separate ANOVAs were conducted, respectively. The ANOVAs included the within-factors laterality (left: F3, FC3; central: Fz, FCz, right electrodes: $F 4, F C 4$ ), and row (F-row and FC-row) and compatibility (COMP, INCOMP, NO-GO). The frontal P3a analysis included only the within-factor compatibility (COMP, INCOMP, and NO$\mathrm{GO})$. Two single analyses of the response- locked ERPs ( $\mathrm{Ne} / \mathrm{Nc}$ and $\mathrm{Pe} / \mathrm{Pc}$ ) included the within factor correctness alone (correct vs. incorrect responses). The factor group (ADHD, SIB, and CON) was always included as between-factor.

\section{RESULTS:}

\subsection{Subject characteristics}

There were fewer females in the ADHD group, but there were no significant differences in age $(F(2,36)=1.8, p=.17)$ or IQ between the 3 groups (Fb1). For symptom ratings we focus on the CPRS that did not differ qualitatively from the CTRS, and on the principle subscales that reflect diagnostic subgroups. The 3 groups

Table 1:

Characteristics of the 3 subject groups, including Conners symptom ratings (means with standard deviations in italics).

\begin{tabular}{|c|c|c|c|c|c|c|c|c|c|c|}
\hline Group & $\mathbf{N}$ & $\begin{array}{l}\text { Gender } \\
(\mathrm{m} / \mathrm{f})\end{array}$ & $\begin{array}{l}\text { Age } \\
\text { (years) }\end{array}$ & IQ & Inattention & $\begin{array}{l}\text { ANOVA } \\
\text { vs. ADHD } \\
\text { (df 1,25) }\end{array}$ & Hyperactivity & $\begin{array}{l}\text { ANOVA } \\
\text { vs. ADHD } \\
\text { (df } 1,25)\end{array}$ & $\begin{array}{l}\text { Sum } \\
\text { of vs } \\
\text { symptoms }\end{array}$ & $\begin{array}{c}\text { ANOVA } \\
\text { ADHD } \\
\text { (df 1,25) }\end{array}$ \\
\hline \multirow[t]{2}{*}{ ADHD } & 15 & $14 / 1$ & 13.9 & 104 & 72.5 & & 76.7 & & 77.3 & \\
\hline & & & 1.6 & 11.8 & 9.2 & & 11.9 & & 11.1 & \\
\hline \multirow[t]{2}{*}{ Siblings } & 12 & $5 / 7$ & 14.5 & 106 & 52.3 & $\mathrm{~F}=24.7 * *$ & $55.2 *$ & $\mathrm{~F}=27.5 * *$ & 54.5 & $\mathrm{~F}=27.3 * *$ \\
\hline & & & 1.8 & 11.9 & 12.1 & & 8.6 & & 11.4 & \\
\hline \multirow[t]{2}{*}{ Controls } & 12 & $3 / 9$ & 13.2 & 105 & 49.8 & $\mathrm{~F}=44.2 * *$ & 49.1 & $\mathrm{~F}=45.7 * *$ & 49.6 & $\mathrm{~F}=53.3 * *$ \\
\hline & & & 1.5 & 11.5 & 8.4 & & 8.5 & & 7.9 & \\
\hline
\end{tabular}

$* * \mathrm{p}<.001$

* Controls vs. siblings, hyperactivity ratings $(\mathrm{F}(1,22)=3.1, \mathrm{p}<.10)$; no differences for controls vs. siblings on inattentive or summed ratings

Table 2:

\begin{tabular}{lllllll}
\hline $\begin{array}{c}\text { Response } \\
\text { Condition }\end{array}$ & $\begin{array}{l}\text { RT } \\
\text { COMP }\end{array}$ & $\begin{array}{l}\text { RT } \\
\text { INCOMP } \\
\text { Correct trial } \\
\text { after error }\end{array}$ & $\begin{array}{l}\text { RT } \\
\text { Slowing }\end{array}$ & $\begin{array}{l}\text { Error rate } \\
\text { COMP }\end{array}$ & $\begin{array}{l}\text { Error rate } \\
\text { INCOMP }\end{array}$ & $\begin{array}{l}\text { Error rate } \\
\text { No-Go }\end{array}$ \\
\hline \multicolumn{1}{c}{ Group } & & & & & & \\
ADHD & $332(58)$ & $419(85)$ & $113(48)$ & $4.6(5.9)$ & $25.5(17.9)$ & $15.8(19.3)$ \\
Siblings & $367(67)$ & $454(48)$ & $111(103)$ & $4.8(7.1)$ & $22.5(24.4)$ & $8.4(9.8)$ \\
Controls & $344(50)$ & $442(45)$ & $85(59)$ & $2.4(2.4)$ & $18.0(12.8)$ & $8.0(9.4)$ \\
\hline
\end{tabular}

$\mathrm{RT}=$ Reaction time (milliseconds); COMP/INCOMP = compatible/incompatible conditions 
$(F<1)$. For symptom ratings we focus on the CPRS that did not differ qualitatively from the CTRS, and on the principle subscales that reflect diagnostic subgroups. The 3 groups differed on the CPRS (inattention/hyperactivity/sum, $\mathrm{F}(2,36)=$ 21.8 / 29.0 / 28.2, $p<.001)$. These showed the ADHD group with higher symptom ratings than the siblings or the controls (see Table 1 for statistics). The siblings showed marginally more symptoms than the controls, but this was only significant for ratings of hyperactivity (Table 1 ).

\subsection{Behavioural data}

There was no significant main effect of group on RT $(F(2,25)=.92, p=.41)$ or error rate $(F(2,35)=.71, p=.50)$, although descriptively the ADHD group tended to respond faster and make more errors than the healthy adolescents (Table 2). RTs were faster in the compatible than in the incompatible condition (means 346 and $437 \mathrm{~ms}$, respectively; $F(1,35)=28.5, p<$ .001). This effect did not interact with the factor group. All three groups showed a markedly slower RT on the first correct response after an error (mean $+103 \mathrm{~ms}$ ) in comparison with RTs on serially correct responses (mean -4 ms; pb.001). But there were no significant differences between the groups $(F(2,35)=.53, p=$ .60; Table 2). For all three groups there was a strong effect of compatibility on error rate; $F(2,70)=36.7 p<.001$. The incompatible condition yielded the highest error rate and also the No-go condition elicited more errors than the compatible condition (means: 21.6\%; compatible: 3.9\%; No-go: $10.7 \%$; all Fs $(1,36)>15.3$, all ps < .001). Again, also this effect did not interact with the factor group.

\subsection{ERP data: N2}

The N2 peak amplitude (Fig. 1) was highest at midline electrodes $(-5.4 \mu \mathrm{V})$ when compared to left $(-3.2 \mu \mathrm{V})$ or right electrodes $(-3.3 \mu \mathrm{V}$; both $\mathrm{Fs}(1,36)>28.2$, both ps <.001; main effect of laterality: $F$
$(2,70)=5.9, p<.01)$. There was an interaction of row $\times$ group $(F(2,35)=6.1$, $p<.01)$. Post hoc tests revealed a significantly higher N2 amplitude for the controls $(-7.1 \mu \mathrm{V})$ compared to the ADHD group $(-3.6 \mu \mathrm{V})$ at frontal electrodes $(F(1$, $25)=5.3, p<.05$; Fig. 2 and Table 3). Compatibility did not significantly affect theN2 amplitude and analysis of peak latencies also showed no significant effect, possibly due to high variability in the data and the conservative inclusion of gender as a co-variable.

\subsection{ERP data: the P3a}

The P3a amplitude varied with the experimental condition (Fig.1). A main effect of compatibility $(F(2,70)=5.7, p<$ .01) showed that a larger amplitude occurred in the No-go than in the incompatible condition (mean 9.5 vs. 6.4 $\mu \mathrm{V}$, respectively: $\mathrm{F}(1,36)=12.0 ; \mathrm{p}<.01)$ or in the compatible condition (mean $1.2 \mu \mathrm{V}$ : $F(1,36)=84.8 ; p<.001)$. The latter two conditions also differed significantly ( $F(1$, 36) $=44.8 ; p<.001)$.

Group interacted with the factor compatibility $(F(4,70)=2.7 ; p<.05)$ such that within both the control and sibling groups P3a amplitude increased from compatible to incompatible and then to the No-go condition (all Fs $(1,11)>4.9$; all ps < .05; Table 3). However, for the ADHD group (Table 3 ) there was no difference between P3a amplitudes in the No-go and incompatible conditions $(p=.58)$. Amplitudes in the compatible condition were smaller than either in the incompatible or the No-go condition (Fs $(1,14)>13.5$; ps < .01).

3.5. ERP data: correct negativity (Nc), error negativity ( $\mathrm{Ne}$ ) and error positivity (Pe)

As there were not enough acceptable trials with errors of commission in the Nogo condition to calculate the $\mathrm{Ne}$, the analysis is restricted to the incompatible 
condition. As expected there was a large difference between the amplitude of $\mathrm{Ne}$ and Nc (means -12.7 vs. $-6.0 \mu \mathrm{V}: \mathrm{F}(1,35)$ $=4.2 ; \mathrm{p}<.05$ : Fig. 3). Considering the three groups of subjects there were no group differences in $\mathrm{Ne}$ and $\mathrm{Nc}$ amplitude (main effect group: $F(2,35)=1.2, p=.32$ ) nor an interaction of correctness $\times$ group $(F(2,35)=1.6, p=.21)$. Analysis of the $\mathrm{Ne} / \mathrm{Nc}$-latencies revealed no significant effects.

The early Pe (200-250 ms), which was pronounced at $\mathrm{Cz}$, was more positive after Figure 1. incorrect than correct responses (mean +6.1 vs. $-11.1 \mu \mathrm{V}: \mathrm{F}(1,35)=9.2 ; p<.01)$. The late Pe (250 to $350 \mathrm{~ms}$ ) was also more positive after incorrect than correct responses (mean +3.4 vs. $-5.9 \mu \mathrm{V}, \mathrm{F}(1,35)$ $=8.2 ; \mathrm{p}<.01)$. But neither the group main effects (both Fs $(2,35)<1.1$, both ps $>.35$ ) nor the group $\times$ correctness interactions (both Fs $(2,35)<2.3$, both ps > .12) attained significance for the early and late $\mathrm{Pe}$, respectively.

Grand average ERPs at $\mathrm{Fz}$ and $\mathrm{FCz}$ for the 3 subject groups to compatible (COMP), incompatible (INCOMP) and No-go stimuli: The dotted vertical line represents the flanker onset. The time point zero corresponds to the target onset.

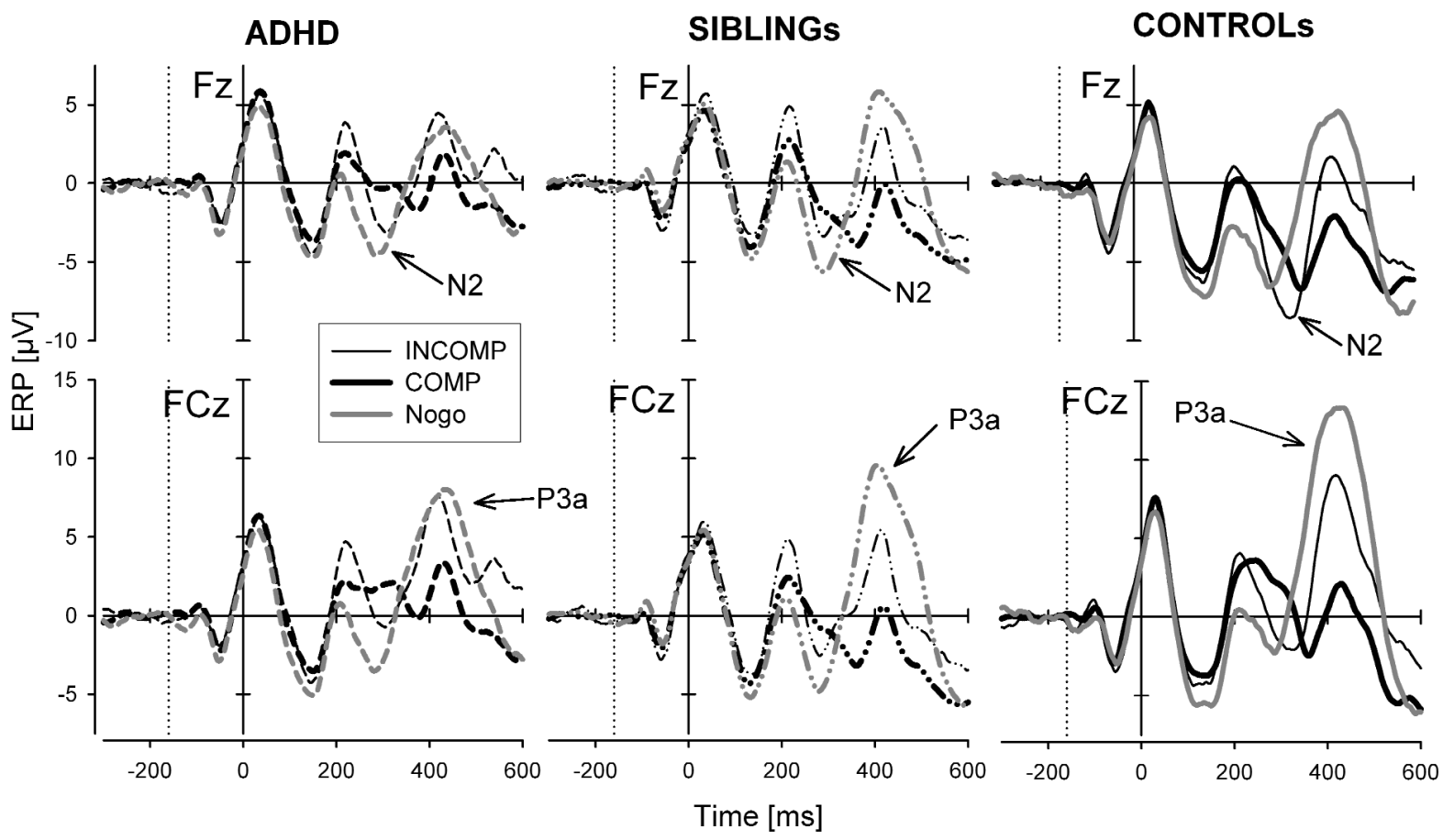

\section{DISCUSSION}

In this report we used a single task with asynchronous distracting flanker stimuli, incongruity between target and flanker arrow-heads and a No-go cue to examine the ability of adolescents with ADHD, their healthy siblings and healthy controls to suppress prepotent response tendencies. The associated processes were indexed with stimulus-locked cognitive ERPs.
Response-locked potentials were recorded to measure how errors made in these conditions were monitored. We predicted that adolescents with ADHD would be deficient behaviourally and physiologically, and that this would be partially reflected in the performance of their siblings without a diagnosis. The latter effect would facilitate a description of a potential endophenotype underlying such processes. 
Overt performance did not show major differences between groups, although Nogo errors were numerically increased for the patients. Processing of the target, indexed by the N2, was reduced in the ADHD group especially at frontal electrode positions. The P3a that followed was larger in the No-Go than in the incompatible condition for the comparison group and the siblings. However the P3a recorded from the ADHD group did not differentiate between conditions. The $\mathrm{Ne}$ response on error trials was not significantly different between groups. The positive response $(\mathrm{Pe})$ that followed the $\mathrm{Ne}$ (compared to the potentials after a correct response) did also not differentiate between groups. We discuss these findings on the way adolescents with ADHD process information and monitor their responses in the context of similar recent studies.

\section{Figure 2.}

Topography of the N2 potential for the 3 subject groups to incompatible and No-go stimuli.

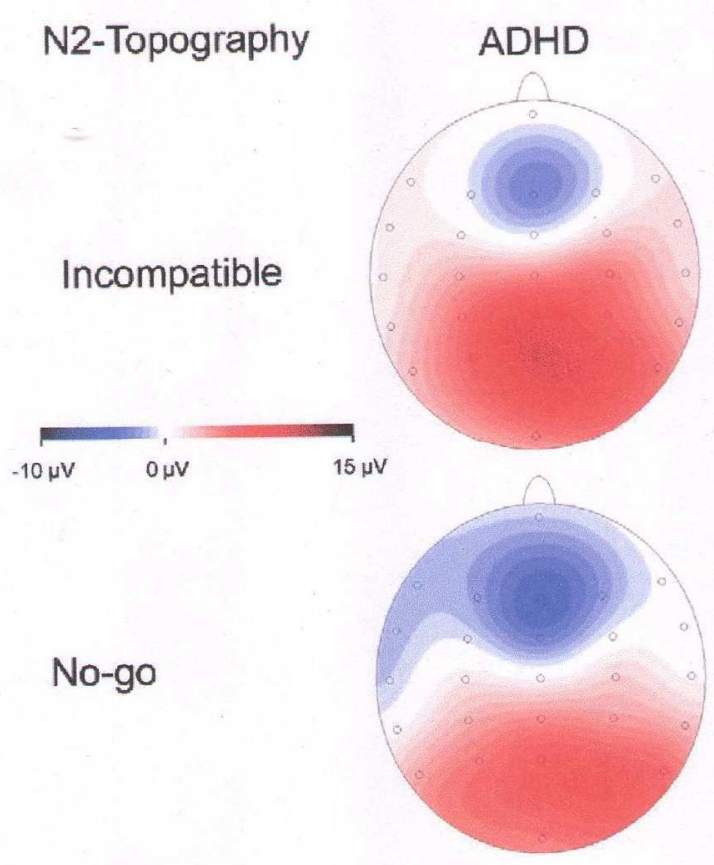

\subsection{Subjects and behaviour}

The subject groups were well matched for age and IQ, although proportionately fewer females were represented in the ADHD group. However, this reflects the normal prevalence of ADHD (Buitelaar et al., 2006), where girls usually show similar ERP characteristics to boys in conditions like the one used here (Liotti et al., 2007). Because of the different gender ratio between groups we included gender as a covariate in order to control for a possible influence. Thus, this control is rather

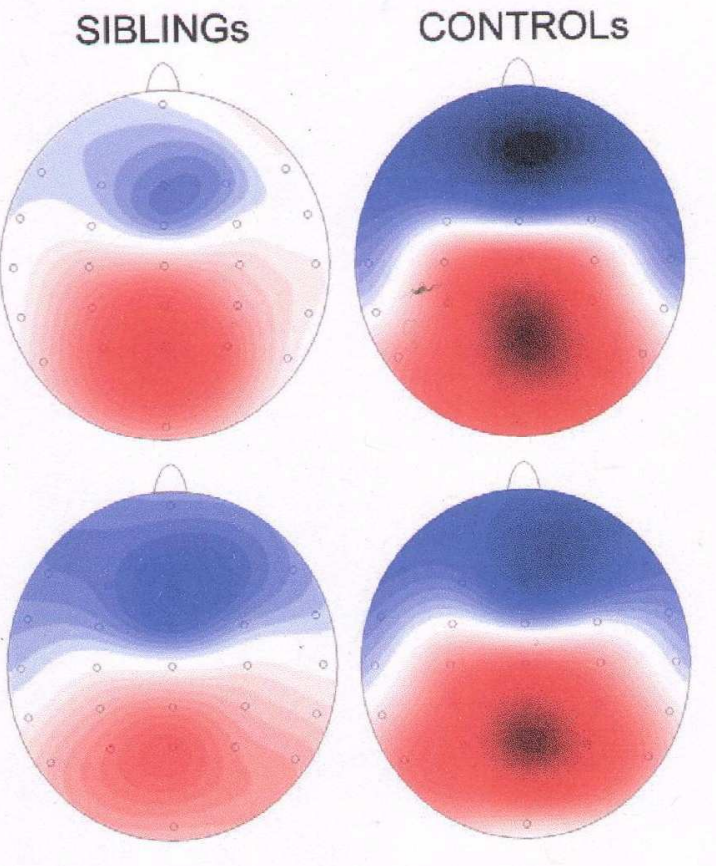

conservative considering also the relatively low number of participants in the three groups. A more even matching of the gender ratio and increased group size is recommended in future studies.

As expected, the incompatible stimuli elicited longer RTs and more errors than compatible stimuli. The error rates were marginally higher, but in the range of those of young adults reported from earlier studies with a similar task (Kopp et al., 1996b; Willemssen et al., 2004). No-go stimuli also elicited more errors than the 
straightforward compatible condition of the flanker task. The contrasting low error rate after compatible stimuli shows that there was a strong tendency to respond to the flankers, which may prove correct in the compatible condition but lead to errors in the other conditions.

Descriptively the ADHD group tended to respond impulsively: they responded marginally faster and made more errors than the two comparison groups. However, the differences were not significant. The error rates of siblings resembled the ADHD group but were also non-significantly higher than the controls. Age and IQ are unlikely to confound the comparisons as the groups were well matched on these features and regressions have been calculated for age on the relevant dependent variables without any significant result. Nonetheless the standard deviations for most of these measures were markedly smaller in the controls, which underlines the frequently reported feature of variability between subjects with symptoms of ADHD (Oades and Christiansen, 2008; Di Martino et al., 2008). Participants in each group showed longer RTs for correct responses after an error than after a correct response, i.e. normal post-error slowing. This result ran counter to our expectation (see Introduction), but is consistent with two other studies of action monitoring in ADHD children (Burgio-Murphy et al., 2007; Van Meel et al., 2007). Clearly, the absence of the normal slowing of a correct response following an error should not be considered as a cardinal feature of adolescents with ADHD, as previously suggested (Sergeant and van der Meere, 1988).
Figure 3.

Grand average response-locked ERPs at $\mathrm{FCz}$ and $\mathrm{Cz}$ for the three subject groups to correct and incorrect responses in the incompatible condition. The time point zero corresponds to the response onset. Arrows point to the $\mathrm{Ne}$ and Pe components.

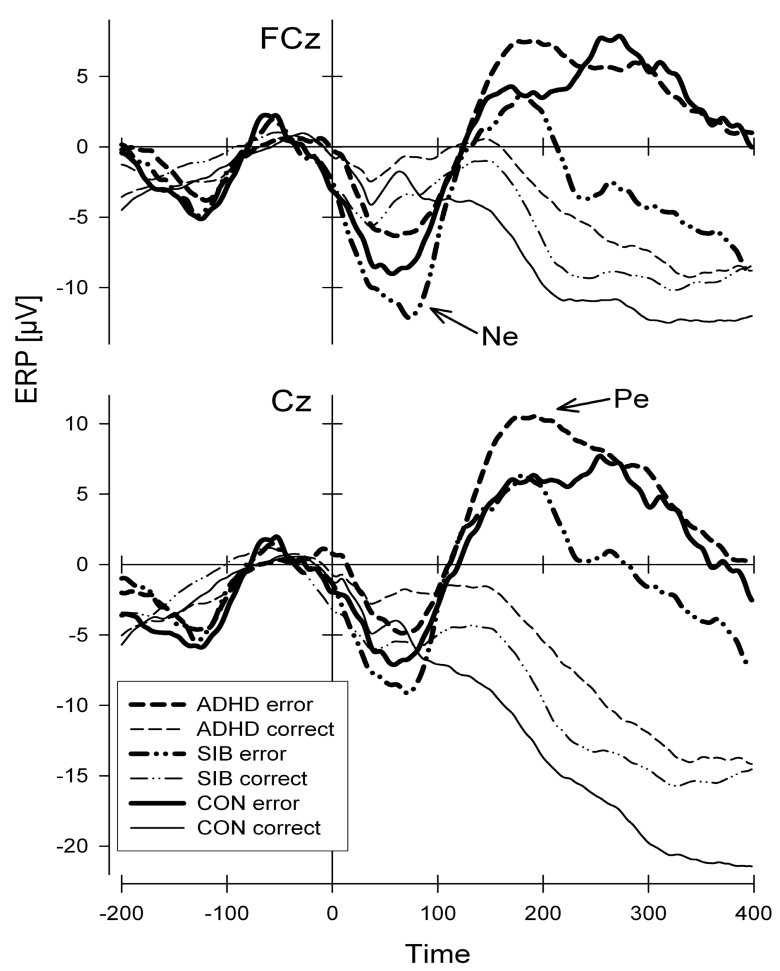

\subsection{Stimulus processing}

The frontal N2 was especially marked on incompatible and No-go trials. This is in line with the results from many studies of conflict conditions requiring effortful classification of stimuli, control of interference and selection of correct responses in young adults (van Veen and Carter, 2002; Schmajuk et al., 2006; Gajewsky et al., 2008). However, the differences between compatibility conditions did not attain statistical significance (main effect of compatibility) probably due to high variability in the data. 
Table 3:

Amplitudes $(\mu \mathrm{V})$ of stimulus and response-locked ERPs for 3 groups of subjects

(Standard deviations in parentheses).

\begin{tabular}{|c|c|c|c|}
\hline Group component & ADHD & SIBs & $\mathrm{CON}$ \\
\hline \multicolumn{4}{|c|}{$\underline{\text { Stimulus-locked ERPs }}$} \\
\hline \multicolumn{4}{|l|}{$\begin{array}{l}\text { N2 peak amplitude } \\
\text { (COMP, INCOMP, No-go) }\end{array}$} \\
\hline $\begin{array}{l}\text { Left/Midline/Right } \\
\text { Frontal/Fronto-central }\end{array}$ & $\begin{array}{l}-2.1(3.8) /-4.3(5.4) /-1.9(4.2) \\
-3.6(4.7) /-1.9(4.3)\end{array}$ & $\begin{array}{l}-3.4(3.6) /-5.6(4.9) /-3.5(3.9) \\
-4.8(4.5) /-3.5(3.9)\end{array}$ & $\begin{array}{l}-4.0(5.3) /-6.5(5.7) /-4.4(5.6) \\
-7.1(5.5) /-2.9(5.6)\end{array}$ \\
\hline \multicolumn{4}{|l|}{ P3a at $\mathrm{FCz}$} \\
\hline (No-go/INCOMP/COMP) & $7.4(5.8) / 6.7(6.3) / 2.4(5.0)$ & $8.7(6.5) / 4.0(4.1) /-0.3(3.5)$ & $13.0(11.1) / 8.3(10.7) / 1.3(4.9)$ \\
\hline \multicolumn{4}{|c|}{$\underline{\text { Response-locked ERPs }}$} \\
\hline \multicolumn{4}{|c|}{$\mathrm{Ne}(\mathrm{Nc})$ at FCz (INCOMP) } \\
\hline $\mathrm{Ne} / \mathrm{Nc}$ & $-9.5(6.1) /-5.1(4.5)$ & $-16.3(7.8) /-6.5(4.7)$ & $-13.1(8.9) /-6.5(5.0)$ \\
\hline \multicolumn{4}{|l|}{$\mathrm{Pe} / \mathrm{Pc}$ at $\mathrm{Cz}$ (Incomp) } \\
\hline Early $\mathrm{Pe} / \mathrm{Pc}$ & $9.3(12.1) / 7.2(9.3)$ & $2.0(11.7) /-12.0(6.2)$ & $6.0(6.7) /-15.1(9.4)$ \\
\hline
\end{tabular}

In the ADHD group the frontal N2 was generally reduced compared to the controls, suggesting a general decline of the efficiency of the processes necessary for controlled response selection in ADHD patients. This is in line with other reports on the $\mathrm{N} 2$ in ADHD children from visual Go/No-go tasks (Pliszka et al., 2000; Barry et al., 2003; Smith et al., 2004), also suggesting declined efficiency of response inhibition. There is evidence that N2 in Nogo trials is generated, at least in part by a right frontal source (Oades, 1998; Ladouceur et al., 2007), most probably located in the right inferior frontal gyrus (IFG: Aron et al., 2004). This is reminiscent of the right-lateral attenuation of a related component, the mismatch negativity, (Oades et al., 1996) that also has an IFG source (Jemel et al., 2002). Recent neuroimaging studies also emphasize reduced volume and decreased connectivity within the frontal lobe of patients with ADHD (Valera et al., 2007; Makris et al., 2008). Although there was not an interaction with compatibility and group in our data, there were large numerical differences when comparing the No-go-N2 between ADHD patients and controls at the right frontal F4 electrode (4.5 $\mu \mathrm{V}$ vs. $7.1 \mu \mathrm{V}$, respectively). Together with the significant reduction of the frontal N2 in the ADHD group our results suggest a declined efficiency of response control.

The fronto-central P3a amplitude in the compatible condition did not differ between groups. This is consistent with other findings (Sunohara et al., 1997). However, the amplitude of the $\mathrm{P3a}$ in normal adolescents and siblings was small in compatible trials, larger in incompatible trials, and even larger in No-go trials. Using the same task parameters we have observed that the flankers elicit a dip in the lateralised readiness potential which is then actively inhibited and reversed (Willemssen et al., 2004). Assuming the P3a reflects this process, it would be expected to be large when a response is suppressed on a No-go trial. The enhancement of the P3a in the No-go vs. incompatible trials was absent in the 
adolescents with ADHD. Hence our data suggest that the controlled executive process leading to response suppression in No-go trials is attenuated in ADHD. The trend for an increased error rate in the ADHD group on No-go trials supports this interpretation. In incompatible trials the probably automatic inhibition process is present in ADHD as in normals, while the extra, controlled, inhibition necessary in No-go trials is hardly activated in ADHD. Consistent with this result and interpretation, others have reported an association between $\mathrm{P} 3 \mathrm{a}$ amplitude and errors of commission made on a continuous performance task (Banaschewski et al., 2003), and that ADHD children show a reduced $\mathrm{P} 3 \mathrm{a}$ amplitude following successfully inhibited responses on a stop-task (Liotti et al., 2005).

\subsection{Post-response processing}

Despite the significant difference between the small $\mathrm{Nc}$ after correct responses and the large $\mathrm{Ne}$ after error responses there were no significant group differences for the potentials. At a descriptive level it can be seen in Fig. 3 that the Ne component in the siblings and controls is larger than that of the ADHD group, but that these differences were not significant. Hence the $\mathrm{Ne}$ in our ADHD sample was not significantly reduced compared to siblings and healthy controls. This may also explain the normal posterror slowing in all our subjects.

Comparison with other published studies is difficult. Ne amplitude in groups of ADHD children have been reported to be smaller (Liotti et al., 2005; Van Meel et al., 2007; Albrecht et al., 2008), to not differ (Wiersema et al., 2005; Jonkman et al., 2007) or to be larger (Burgio-Murphy et al., 2007) than in control groups. Potential reasons for the differences are numerous, and include the nature of the task (discrimination, flanker, stop-task,
Go/No-go), the analysis (base-lining, reference to $\mathrm{Nc}$ ) and patient selection (subgroup, comorbidity). We conclude firstly, that an altered $\mathrm{Ne}$ is probably dependent of the nature of the error and the type of task used. Secondly, one cannot expect that any child with a diagnosis of ADHD will exhibit an altered $\mathrm{Ne}$. The characteristics of a subgroup that might show an altered expression of $\mathrm{Ne}$ have not yet been described. We recommend further study with rigorous control over task (e.g. comparing two types of task or level of complexity), analysis (e.g. comparing two types of baseline or subtraction analysis) and clearly defined subgroups of children/adolescents with the ADHD diagnosis (e.g. pure vs. comorbid conduct problems).

All groups showed a clear and large Pe with respect to the positivity following a correct response. There were no significant group differences for the early and late $\mathrm{Pe}$. The absence of an unequivocal change in the positivity in the ERP while adolescents with ADHD monitored response for errors is consistent with two recent studies (Burgio-Murphy et al., 2007; Albrecht et al., 2008), but inconsistent with reductions reported by others (Wiersema et al., 2005; Jonkman et al., 2007). As with the $\mathrm{Ne}$ there are potentially several reasons for this inconsistency, of which the most salient concerns the relation between behavioural performance and the $\mathrm{Pe}$ amplitude. More specifically, whereas the first two studies found comparable $\mathrm{Pe}$ amplitudes for patients and controls on the background of comparable behavioural performance (as is the case in the present study), the two last mentioned studies reported increased performance errors and a lower $\mathrm{Pe}$ amplitude for patients compared to controls. This pattern of results fits to the established interpretation of the $\mathrm{Pe}$, most 
probably reflecting a P300-like potential which can be functionally dissociated from the processes subserving the $\mathrm{Ne}$ and that the $\mathrm{Pe}$ is related to error recognition and awareness (Leuthold and Sommer, 1999; Nieuwenhuis et al., 2001; Endrass et al., 2007). Thus, the present result suggests intact error recognition and awareness in adolescents with ADHD compared to healthy controls at least if error performance is comparable. However, reasons for the heterogeneous picture in the literature concerning performance differences between youngsters with ADHD and controls remain unclear, probably depending on patient characteristics and the nature of the task. This has to be resolved in further studies taking these two factors into account.

\section{CONCLUSIONS}

The present study shows a distinct pattern of executive impairment in youngsters with ADHD as recorded by ERPs, namely an attenuation of conscious control, as necessary in No-go trials. These changes were also reflected in a numerically enhanced rate of false alarms. In contrast, the error-related behavioural and ERP activity was not significantly altered: the error-related potentials, $\mathrm{Ne}$ and $\mathrm{Pe}$, were not significantly reduced, and posterior slowing was normal. This shows that an absence of post-error response slowing or deficient error processing on an automatic and conscious level (as reflected in the $\mathrm{Ne}$ and $\mathrm{Pe}$ ) are not defining features of ADHD. In addition, we did not find evidence for a phenotype of ADHD as task performance of the siblings was comparable to the controls. Some other features of the study restrict the generalization of our conclusions. The subject selection procedure and small group sizes did not allow us to control for gender, and restricted the age range available. We chose to use easily discriminable stimuli in a relatively simple task and not investigate the role of task complexity and difficulty. There would be value in future work to examine variations in stimulus and trial intervals, event-rate and time pressure.

\section{References:}

Albrecht, B., Banaschewski, T., Brandeis, D., Heinrich, H., Rothenberger, A., 2005. Response inhibition deficits in externalizing child psychiatric disorders: an ERP study with the Stop-task. Behav. Brain Funct. 1, 22.

Albrecht, B., Brandeis, D., Uebel, H., Heinrich, H., Müller, U.C., Hasselhorn, M., Steinhausen, H.-C., Rothenberger, A., Banaschewski, T., 2008. Action monitoring in boys with attentiondeficit/hyperactivity disorder, their non-affected siblings, and normal control subjects: evidence for an endophenotype. Biol. Psychiatry 64, 615-625.

Allain, S., Carbonell, L., Falkenstein, M., Burle, B., Vidal, F., 2004. The modulation of the Ne-like wave on correct responses foreshadows errors. Neurosci. Lett. 372, 161-166.

Anokhin, A.P., Heath, A.C., Myers, E., 2004. Genetics, prefrontal cortex, and cognitive control: a twin study of eventrelated brain potentials in a response inhibition task. Neurosci. Lett. 368, 314-318.

Aron, A.R., Monsell, S., Sahakian, B.J., Robbins, T.W., 2004. A componential analysis of task-switching deficits associated with lesions of left and right frontal cortex. Brain 127, 1561-1573.

Azizian, A., Freitas, A.L., Parvaz, M.A., Squires, N.K., 2006. Beware misleading cues: perceptual similarity modulates the N2/P3 complex. Psychophysiology 43, 253-260.

Banaschewski, T., Brandeis, D., Heinrich, H., Albrecht, B., Brunner, E., 
Rothenberger, A., 2003. Questioning inhibitory control as the specific deficit of ADHD - evidence from brain electrical activity. J. Neural Transm. $111,841-864$.

Barry, R.J., Johnstone, S.J., Clarke, A.R., 2003. A review of electrophysiology in attention deficit/hyperactivity disorder: II Event-related potentials. Clin. Neurophysiol. 114, 184-198.

Bekker, E.M., Overtoom, C.C.E., Kooij, J.J.S., Buitelaar, J.K., Verbaten, M.N., Kenemans, J.L., 2005. Disentangling deficits in adults with attentiondeficit/hyperactivity disorder. Arch. Gen. Psychiatry 62, 1129-1136.

Biederman, J., 2005. Attentiondeficit/hyperactivity disorder: a selective overview. Biol. Psychiatry 57, 1215-1220.

Brandeis, D., van Leeuwen, T.H., Rubia, K., Vitacco, D., Steger, J., Pascual-Marqui, R.D., Steinhausen, H.-C., 1998. Neuroelectric mapping reveals precursor of stop failures in children with attention deficits. Behav. Brain Res. 94, 111-125.

Broyd, S.J., Johnstone, S.J., Barry, R.J., Clarke, A.R., McCarthy, R., Selikowitz, M., Lawrence, C.A., 2005. The effect of methylphenidate on response inhibition and the event-related potential of children with Attention Deficit/ Hyperactivity Disorder. Int. J. Psychophysiology. 58, 47-58.

Bruin, K.J., Wijers, A.A., 2002. Inhibition, response mode, and stimulus probability: a comparative eventrelated potential study. Clin. Neurophysiol. 113, 1172-1182.

Buitelaar, J.K., Barton, J., Danckaerts, M., Friedrichs, E., Gillberg, C., Hazell, P.L., Hellemans, H., Johnson, M., Kalverdijk, L.J., Masi, G., Michelson, D., Revol, O., San Sebastian, J., Zhang, S., Zuddas, A., 2006. A comparison of North American versus non-North American ADHD study populations. Eur. Child Adolesc. Psychiatry 15, 177-181.

Burgio-Murphy, A., Klorman, R., Shaywitz, S.E., Fletcher, J.M., Marchione, K.E., Holahan, J., Stuebing, K.K., Thatcher, J.E., Shaywitz, B.A., 2007. Error-related event-related potentials in children with attention-deficit hyperactivity disorder, oppositional defiant disorder, reading disorder, and math disorder. Biol. Psychol. 75, 75-86.

Burle, B., Vidal, F., Bonnet, M., 2004. Electroencephalographic no-go potentials in a no-movement context: the case of motor imagery in humans. Neurosci. Lett. 360, 77-80.

Carbonnell, L., Falkenstein, M., 2006. Does the error negativity reflect the degree of response conflict? Brain Res. 1095, 124-130.

Chen, W., Taylor, E.A., 2006. Parental Account of Children's Symptoms (PACS), ADHD phenotypes and its application to molecular genetic studies. In: Oades, R.D. (Ed.), AttentionDeficit/Hyperactivity Disorder and the Hyperkinetic Syndrome: Current Ideas and Ways Forward. Nova Science Publishing Inc., Hauppauge, NY, pp. 320.

Conners, C.K., 2002. Manual for Conners' rating scales. Multi-Health Systems Inc., N. Tonawanda, NY.

Davies, P.L., Segalowitz, S.J., Gavin, W.J., 2004. Development of responsemonitoring ERPs in 7- to 25-year-olds. Dev. Neuropsychol. 25, 355-376.

Debener, S., Ullsperger, M., Siegel, M., Fiehler, K., von Cramon, D.Y., Engel, A.K., 2005.

Trial-by-trial coupling of concurrent electroencephalogram and functional magnetic resonance imaging identifies the dynamics of performance 
monitoring. J. Neurosci. 25, 1173011737.

Dimoska, A., Johnstone, S.J., Barry, R.J., Clarke, A.R., 2003. Inhibitory motor control in children with attentiondeficit/hyperactivity disorder: eventrelated potentials in the stop-signal paradigm. Biol. Psychiatry 54, 13451354.

Di Martino, A., Ghaffari, M., Curchack, J., Reiss, P., Hyde, C., Vannucci, M., Petkova, E., Klein, D.F., Castellanos, F.X., 2008. Decomposing intra-subject variability in children with attentiondeficit/hyperactivity disorder. Biol. Psychiatry 64, 607-614.

Dong, G., Yang, L., Hu, Y., Jiang, Y., 2009. Is N2 associated with successful suppression of behavior responses in impulse control processes? NeuroReport 20, 537-542.

Endrass, T., Reuter, B., Kathmann, N., 2007. ERP correlates of conscious error recognition: aware and unaware errors in an antisaccade task. Eur. J. Neurosci. 26, 1714-1720.

Eriksen, B.A., Eriksen, C.W., 1974. Effects of noise letters upon the identification of a target letter in a non-search task. Percept. Psychophys. 16, 143-149.

Falkenstein, M., Hohnsbein, J., Hoormann, J., Blanke, L., 1991. Effects of crossmodal divided attention on late ERP components. II. Error-processing in choice reaction tasks. Electroencephalogr. Clin. Neurophysiol. 78, 447-455.

Falkenstein, M., Hoormann, J., Christ, S., Hohnsbein, J., 2000. ERP components on reaction errors and their functional significance: a tutorial. Biol. Psychol. 51, 87-107.

Falkenstein, M., Hielscher, H., Dziobek, I., Schwarzenau, P., Hoormann, J., Sunderman, B., Hohnsbein, J., 2001. Action monitoring, error detection and the basal ganglia: an ERP study. NeuroReport 12, 157-161.

Falkenstein, M., Hoormann, J., Hohnsbein, J., 2002. Inhibition-related ERP components: variation with modality, age, and time-on-task. J. Psychophysiol. $16,167-175$.

Fallgatter, A.J., Ehlis, A.-C., Rösler, M., Strik, W.K., Blocher, D., Herrmann, M.J., 2005. Diminished prefrontal brain function in adults with psychopathology in childhood related to attention deficit hyperactivity disorder. Psychiatr. Res. (Neuroimaging) 138, 157-169.

Faraone, S.V., Asherson, P., Image Consortium, 2005a. The molecular genetics of attention deficit hyperactivity disorder: a view from the IMAGE project. Psychiatric Times August 21-23.

Faraone, S.V., Perlis, R.H., Doyle, A.E., Smoller, J.W., Goralnick, J.J., Holmgren, M.A., Sklar, P., 2005b. Molecular genetics of attention deficit hyperactivity disorder. Biol. Psychiatry 57, 1313-1323.

Folstein, J.R., Van Petten, C., Rose, S.A., 2008. Novelty and conflict in the categorization of complex stimuli. Psychophysiology 45, 467-479.

Gajewsky, P.D., Stoerig, P., Falkenstein, M., 2008. ERP-correlates of response selection in a response conflict paradigm. Brain Res. 1189, 127-134.

Gehring, W.J., Goss, B., Coles, M.G.H., Meyer, D.E., Donchin, E., 1993. A neural system for error detection and compensation. Psychol. Sci. 4, 385-390.

Gomes, H., Barrett, S., Duff, M., Barnhardt, J., Ritter,W., 2008. The effects of interstimulus interval on event-related indices of attention: an auditory selective attention test of perceptual 
load theory. Clin. Neurophysiol. 119, 542-555.

Goodman, R., 1997. The strengths and difficulties questionnaire: a research note. J. Child Psychol. Psychiatry 38, 581-586.

Gratton, G., Coles, M.G.H., Donchin, E., 1983. A new method for off-line removal of ocular artifact. Electroencephalogr. Clin. Neurophysiol. 55, 468-484.

Groom, M.J., Bates, A.T., Jackson, G.M., Calton, T.G., Liddle, P.F., Hollis, C., 2008. Event-related potentials in adolescents with schizophrenia and their siblings: a comparison with ADHD. Biol. Psychiatry 63, 784-792.

Hajcak, G., McDonald, N., Simons, R.F., 2003. To err is autonomic: error-related brain potentials, ANS activity, and posterror compensatory behavior. Psychophysiology 40, 895-903.

Henriquez, M., Lopez-Calderon, V., Lopez, V., Rothhammer, P., Zamorano, F., Rothhammer, F., Aboitiz, F., 2006. Electrophysiological correlates for response inhibition in attention deficit/Hyperactivity disorder (ADHD): an ERP analysis of the Go/no-go task. Proceedings of the Second Dual Congress on "Psychiatry and the Neurosciences" Athens, 88.

Hogan, A.M., Vargha-Khadem, F., Kirkham, F.J., Baldeweg, T., 2005. Maturation of action monitoring from adolescence to adulthood: an ERP study. Dev. Sci. 8, 525-534.

Jemel, B., Achenbach, C., Müller, B., Röpcke, B., Oades, R.D., 2002. Mismatch negativity results from bilateral asymmetric dipole sources in the frontal and temporal lobes. Brain Topogr. 15, 13-27.

Johnstone, S.J., Barry, R.J., Clarke, A.R., 2007. Behavioural and ERP indices of response inhibition during a stop-signal task in children with two subtypes of attention deficit hyperactivity disorder. Int. J. Psychophysiology. 66, 37-47.

Jonkman, L.M., Kemner, C., Verbaten, M.N., van Engeland, H., Kenemans, J.L., Camfferman, G., Buitelaar, J.K., Koelega, H.S., 1999. Perceptual and response interference in children with attention-deficit hyperactivity disorder, and the effects of methylphenidate. Psychophysiology 36, 419-429.

Jonkman, L.M., van Melis, J.J.M., Kemner, C., Markus, C.R., 2007. Methylphenidate improves deficient error evaluation in children with ADHD: an event-related brain potential study. Biol. Psychol. 76, 217-229.

Kamarajan, C., Porjesz, B., Jones, K.A., Chorlian, D.B., Padmanabhapillai, A., Rangaswamy, M., Stimus, A.T., Begleiter, H., 2005. Spatial-anatomical mapping of NoGo-P3 in the offspring of alcoholics: evidence of cognitive and neural disinhibition as a risk for alcoholism. Clin. Neurophysiol. 116, 1049-1061.

Konrad, K., Günther, T., Hanisch, C., Herpertz-Dahlmann, B., 2004. Differential effects of methylphenidate on attentional functions in children with attention-deficit/hyperactivity disorder. J. Am. Acad. Child Adolesc. Psych. 43, 191-198.

Konrad, K., Neufang, S., Hanisch, C., Fink, G.R., Herpetz-Dahlmann, B., 2006. Dysfunctional attentional networks in children with attention deficit/ hyperactivity disorder: evidence from an event-related functional magnetic resonance imaging study. Biol. Psychiatry 59, 643-651.

Kopp, B., Mattler, U., Goertz, R., Rist, F., 1996a. N2, P3 and the lateralized readiness potential in a no-go task involving selective response priming. 
Electroencephalogr. Clin. Neurophysiol. 99, 19-27.

Kopp, B., Rist, F., Mattler, U., 1996b. N200 in the flanker task as a neurobehavioral tool for investigating executive control. Psychophysiology 33, 282-294.

Ladouceur, C.D., Dahl, R.E., Carter, C.S., 2004. ERP correlates of action monitoring in adolescence. Ann. N. Y. Acad. Sci. 1021, 329-336.

Ladouceur, C.D., Dahl, R.E., Carter, C.S., 2007. Development of action monitoring through adolescence into adulthood: ERP and source localization. Dev. Sci. 10, 874-891.

Lawrence, V., Houghton, S., Tannock, R., Douglas, G., Durkin, K., Whiting, K., 2002. ADHD outside the laboratory: boys' executive function performance on tasks in videogame play and on a visit to the zoo. J. Abnorm. Child Psychol. 30, 447-462.

Leuthold, H., Sommer, W., 1999. ERP correlates of error processing in spatial S-R compatibility tasks. Clin. Neurophysiol. 110, 342-357.

Liotti, M., Pliszka, S.R., Perez, R., Kothmann, D., Woldorff, M.G., 2005. Abnormal brain activity related to performance monitoring and error detection in children with ADHD. Cortex 41, 377-388.

Liotti, M., Pliszka, S.R., Perez, R., Luus, B., Glahn, D., Semrud-Clikeman, M., 2007. Electrophysiological correlates of response inhibition in children and adolescents with ADHD: influence of gender, age, and previous treatment history. Psychophysiology 44, 936-948.

Loe, I., Feldman, H., 2007. Academic and educational outcomes of children with ADHD. Ambul. Pediatr. 7, 82-90.

Makris, N., Buka, S.L., Biederman, J., Papadimitriou, G.M., Hodge, S.M., Valera, E.M., Brown, A.B., Bush, G.,
Monuteaux, M.C., Caviness, V.S., Kennedy, D.N., Seidman, L.J., 2008. Attention and executive systems abnormalities in adults with childhood ADHD: a DT-MRI study of connections. Cereb. Cortex 18, 1210-1220.

Masaki, H., Falkenstein, M., Stürmer, B., Pinkpank, T., Sommer, W., 2007. Does the error negativity reflect response conflict strength? Evidence from a Simon task. Psychophysiology 44, 579585.

Nieuwenhuis, S., Ridderinkhof, K.R., Blom, J., Band, G.P., Kok, A., 2001. Errorrelated brain potentials are differentially related to awareness of response errors: evidence from an antisaccade task. Psychophysiology 38, 752-760.

O'Connell, R.G., Dockree, P.M., Bellgrove, M.A., Kelly, S.P., Hester, R., Garavan, H., Robertson, I.H., Foxe, J.J., 2007. The role of cingulate cortex in the detection of errors with and without awareness: a high-density electrical mapping study. Eur. J. Neurosci. 25, 2571-2579.

Oades, R.D., 1998. Frontal, temporal and lateralized brain function in children with attention-deficit hyperactivitydisorder: a psychophysiological and neuropsychological viewpoint on development. Behav. Brain Res. 94, 8395.

Oades, R.D., Christiansen, H., 2008. Cognitive switching processes in young people with attention-deficit/ hyperactivity disorder. Arch. Clin. Neuropsychol. 23, 21-32.

Oades, R.D., Dittmann-Balcar, A., Schepker, R., Eggers, C., 1996. Auditory event-related potentials and mismatch negativity in healthy children and those with attention deficit- or Tourette-like symptoms. Biol. Psychol. 43, 163-185. 
Ohlmeier, M.D., Prox, V., Zhang, Y., Zedler, M., Ziegenbein, M., Emrich, H.M., Dietrich, D.E., 2007. Effects of methylphenidate in ADHD adults on target evaluation processing reflected by event-related potentials. Neurosci. Lett. 424, 149-154.

Overbeek, T.J.M., Nieuwenhuis, S., Ridderinkhof, K.R., 2006. Dissociable components of error processing: On the functional significance of the Pe visà-vis the ERN/Ne. J. Psychophysiol. 19, 319-329.

Overtoom, C.C.E., Kenemans, J.L., Verbaten, M.N., Kemner, C., van der Molen, M.W., van Engeland, H., Buitelaar, J.K., Koelega, H.S., 2002. Inhibition in children with attentiondeficit/hyperactivity disorder: a psychophysiological study of the stop task. Biol. Psychiatry 51, 668-676.

Pliszka, S.R., Liotti, M., Woldorff, M.G., 2000. Inhibitory control in children with attention-deficit/hyperactivity disorder: event-related potentials identify the processing component and timing of an impaired right-frontal responseinhibition mechanism. Biol. Psychiatry $48,238-246$.

Prox, V., Dietrich, D.E., Zhang, Y., Emrich, H.M., Ohlmeier, M.D., 2007. Attentional processing in adults with ADHD as reflected by event-related potentials. Neurosci. Lett. 419, 236241.

Rabbitt, P.M.A., 1966. Errors and error correction in choice reaction time tasks. J. Exp. Psychol. 71, 264-272.

Santesso, D.L., Segalowitz, S.J., Schmidt, L.A., 2006. Error-related Electrocortical responses in 10-year-old children and young adults. Dev. Sci. 9, 473-481.

Sattler, J.M., 1992. Assessment of Children: Behavioral and Clinical
Applications, 3rd ed. J.M. Sattler Publ. Inc., San Diego.

Schachar, R.J., Chen, S., Logan, G.D., Ornstein, T.J., Crosbie, J., Ickowicz, A., Pakulak, A., 2004. Evidence for an error monitoring deficit in attention deficit hyperactivity disorder. J. Abnorm. Child Psychol. 32, 285-293.

Schmajuk, M., Liotti, M., Busse, L., Woldorff, M.G., 2006. Electrophysiological activity underlying inhibitory control processes in normal adults. Neuropsychologia 44, 384-395.

Segalowitz, S.J., Davies, P.L., 2004. Charting the maturation of the frontal lobe: an electrophysiological strategy. Brain Cogn. 55, 116-133.

Sergeant, J.A., van der Meere, J.J., 1988. What happens when the hyperactive child commits an error? Psychiatr. Res. 24, 157-164.

Siklos, S., Kerns, K.A., 2004. Assessing multitasking in children with ADHD using a modified Six Elements Test. Arch. Clin. Neuropsychol. 19, 347-361.

Smith, J.L., Johnstone, S.J., Barry, R.J., 2004. Inhibitory processing during the Go/No-Go task: an ERP analysis of children with attentiondeficit/hyperactivity disorder. Clin. Neurophysiol. 115, 1320-1331.

Spira, E.G., Fischel, J.E., 2005. The impact of preschool inattention, hyperactivity, and impulsivity on social and academic development: a review. J. Child Psychol. Psychiatry 46, 755-773.

Sunohara, G.A., Voros, J.G., Malone, M.A., Taylor, M.J., 1997. Effects of methylphenidate in children with attention deficit hyperactivity disorder: a comparison of event-related potentials between medication responders and non-responders. Int. J. Psychophysiol. 27, 9-14. 
Swanson, J.M., Kinsbourne, M., Nigg, J., Lanphear, B., Stefanatos, G.A., Volkow, N., Taylor, E., Casey, B.J., Castellanos, F.X., Wadhwa, P.D., 2007. Etiologic subtypes of attention deficit/ hyperactivity disorder: brain imaging, molecular genetic and environmental factors and the dopamine hypothesis. Neuropsychol. Rev. 17, 39-59.

Szmalec, A., Verbruggen, F., Vandierendonck, A., De Baene, W., Verguts, T., Notebaert, W., 2008. Stimulus ambiguity elicits response conflict. Neurosci. Lett. 435, 158-162.

Taylor, E.A., Sandberg, S., Thorley, G., Giles, S., 1991. The Epidemiology of Childhood Hyperactivity. Oxford University Press, Oxford, UK.

Valera, E.M., Faraone, S.V., Murray, K.E., Seidman, L.J., 2007. Meta-analysis of structural imaging findings in attentiondeficit/hyperactivity disorder. Biol. Psychiatry 61, 1361-1369.

Van Meel, C.S., Heslenfeld, D.J., Oosterlaan, J., Sergeant, J.A., 2007. Adaptive control deficits in attentiondeficit/hyperactivity disorder (ADHD): the role of error processing. Psychiatr. Res. 151, 211-220.

van Veen, V., Carter, C.S., 2002. The timing of action-monitoring processes in the anterior cingulate cortex. J. Cogn. Neurosci. 14, 593-602.

Vidal, F., Burle, B., Bonnet, M., Grapperon, J., Hasbroucq, T., 2003. Error negativity on correct trials: a re-examination of available data. Biol. Psychol. 64, 265282.

Wiersema, J.R., van der Meere, J.J., Roeyers, H., 2005. ERP correlates of impaired error monitoring in children with ADHD. J. Neural Transm. 112, 1417-1430.

Wiersema, J.R., van der Meere, J.J., Roeyers, H., 2007. Developmental changes in error monitoring: an eventrelated potential study. Neuropsychologia 45, 1649-1657.

Wiersema, J.R., van der Meere, J.J., Roeyers, H., Van Coster, R., Baeyens, D., 2006. Event rate and event-related potentials in ADHD. J. Child Psychol. Psychiatry 47, 560-567.

Willemssen, R., Hoormann, J., Hohnsbein, J., Falkenstein, M., 2004. Central and parietal event-related lateralizations in a flanker task. Psychophysiology 41, 762-771.

Yeung, N., Cohen, J.D., Botvinick, M.M., 2004. The neural basis of error detection: conflict monitoring and the error-related negativity. Psychol. Rev. 111, 931-959.

Yordanova, J., Falkenstein, M., Hohnsbein, J., Kolev, V., 2004. Parallel systems of error processing in the brain. Neuroimage 22, 590-602. 